\title{
Study of thermal properties of polyethylene and polypropylene nanocomposites with long alkyl chain-substituted POSS fillers
}

\author{
Arkadiusz Niemczyk $^{1} \cdot$ Katarzyna Dziubek $^{1} \cdot$ Beata Sacher-Majewska $^{1} \cdot$ \\ Krystyna Czaja $^{1} \cdot$ Michał Dutkiewicz $^{2} \cdot$ Bogdan Marciniec $^{2}$
}

Received: 15 November 2015/Accepted: 21 April 2016/Published online: 7 May 2016

(c) The Author(s) 2016. This article is published with open access at Springerlink.com

\begin{abstract}
The effect of incorporation of octakis(\{alkyl $\}$ dimethylsiloxy)octasilsesquioxanes molecules with $n$-octyl, $n$-octadecyl and 4-methyl-hexyl substituents on thermal properties of polypropylene (PP), low-density polyethylene (LDPE) and high-density polyethylene (HDPE) was investigated. Thermal properties of those composite materials were evaluated by means of the differential scanning calorimetry (DSC) and thermogravimetric analysis (TG) methods. The type and mass\% content of POSS nanofillers influenced the crystallization and melting properties as well as thermal stability of the obtained polyolefin nanocomposites. The incorporated POSS particles-acting as nucleating agents-improved the crystallization process of those polyolefin materials. The POSS nanofiller with $n$-octyl substituents turned out the most effective nucleating agent. The addition of POSS nanofiller particles into the polyolefin matrix affected the melting behavior of the nanocomposites obtained, decreasing their melting temperatures. Thermal stability under nitrogen as well as in air atmosphere was most significantly enhanced for polyolefin nanocomposites contained the POSS with $n$-octadecyl substituents. That may result from improved compatibility of the POSS structure with long $n$-alkyl chain substituents at the silicon-oxygen
\end{abstract}

This paper is the post-conference publication of CCTA12.

Katarzyna Dziubek

katarzyna.dziubek@uni.opole.pl

1 Faculty of Chemistry, Opole University, Oleska 48, 45-052 Opole, Poland

2 Centre for Advanced Technologies, Adam Mickiewicz University, Umultowska 89C, 61-614 Poznań, Poland core. The uniform dispersion of the long $n$-alkyl chainsubstituted POSS was confirmed by SEM analysis.

Keywords Polyolefin matrix (nano)composites . Polyhedral oligomeric silsesquioxanes - Thermal properties $\cdot$ Thermal stability $\cdot$ Nucleating agents

\section{Introduction}

New polymer materials attracted a great deal of interest from both the academic and industrial points of view over the last two decades. Special attention was paid to the nanocomposites with polyhedral oligomeric silsesquioxanes (POSS) fillers [1].

POSS particles generally have diameters in the range of 1-3 nm, and they are considered to be the smallest possible particles of silica [2-6]. The POSS structure can be expressed by the general formula $\left(\mathrm{RSiO}_{3 / 2}\right)_{\mathrm{n}}$, where $\mathrm{R}$ is a reactive or non-reactive group and $n$ can take the values of $6,8,10$ or higher $[2,4,6]$. The possibility to modify the POSS structure within a wide range is the unique attribute of those compounds. The silicon-oxygen POSS cores can be formed as random, ladder, cage or partial cage structures [2, 5-7]. Moreover, different kinds and numbers of substituents can be attached to the silicon atoms in the POSS cage $[2,4,6]$. This could open up the opportunity to adjust the POSS properties to meet the needs of a specific application by the structural control [8-11].

High thermal and chemical stability of POSS molecules make them promising candidates as nanofillers for polymer materials because of their silica-like structures and unique architectures [11-15]. POSS particles have been successfully incorporated into various polymers (polyolefins, polyesters, polyamides, polystyrenes, etc.), and the 
addition of POSS particles improved thermal, mechanical and rheological properties of the nanocomposite materials $[7,16,17]$. Moreover, the properties of POSS-containing polymer nanocomposites are dependent on both the chemistry of the substituents attached to the silicon-oxygen POSS core and the content of the POSS nanofiller in composite materials $[7,11,16,17]$.

One of the most important factors which define applicability of POSS-containing polymer nanocomposites is to understand the effect of POSS nanofillers into the polymeric matrix on thermal properties of the polymer nanocomposites obtained [18, 19].

As regards POSS-filled polyolefin nanocomposites, many investigations were focused on the influence of alkyl substituents on the $T_{8}$ POSS core on thermal properties of those materials [20, 21]. It was found that POSS particles might act as effective nucleating agents, which accelerate crystallization of polymers [20-22]. Moreover, the presence of POSS nanofillers clearly improved thermal stability of those materials [20, 23, 24]. However, it should be mentioned that the papers published to date covered mainly the properties of polyolefin/POSS nanocomposites which contained POSS molecules with relatively short alkyl chain substituents (from methyl to iso-octyl) [20-22, 25-30]. Only few papers related to nanocomposites with long alkyl chain substituents (from $n$-octyl to $n$-octadecyl) on the $T_{8}$ POSS core $[31,32]$ and most of those studies focused on PP/POSS [20-22, 25, 28-30] and LDPE/POSS [26, 27, 31, 32] nanocomposites, while studies on HDPE/POSS nanocomposites were limited [33].

The goal of this work was to study the structural effects of long alkyl chain substituents on the $T_{8}$ POSS core on thermal properties of various polyolefin/POSS nanocomposites. The idea of adding POSS molecules with long alkyl chain substituents into the polyolefin matrix was based on the assumption that long alkyl chains would enhance compatibility of the filler particles with polymer chains. Dispersion of POSS nanofillers in the matrix might hence be improved. Therefore, octakis $(\{n$-octyl $\}$ dimethylsiloxy)octasilsesquioxane (POSS8), octakis(\{n-octadecyl $\}$ dimethylsiloxy)octasilsesquioxane (POSS18) and octakis(\{4-methyl-hexyl $\}$ dimethylsiloxy)octasilsesquioxane (POSS7b) were melt-blended within our study with commercially available polyolefins such as polypropylene (PP), low-density polyethylene (LDPE) and high-density polyethylene (HDPE). The influence of the structures of long alkyl chains on the $T_{8}$ POSS core and the influence of the amount of the POSS nanofiller present in the matrix on thermal properties was studied using differential scanning calorimetry (DSC) and thermogravimetric analysis (TG). Based on the results, the role of POSS particles as nucleating agents and the impacts of POSS nanofillers on the thermal stability of POSS-containing polyolefin nanocomposites were discussed.

\section{Experimental}

\section{Materials}

Polypropylene (PP) Moplen HP 400R (MFR $=23 \mathrm{~g} \times$ $\left.10 \mathrm{~min}^{-1} ; 230{ }^{\circ} \mathrm{C} \times 2.16 \mathrm{~kg}^{-1}\right)$, low-density polyethylene (LDPE) Lupolen $3020 \mathrm{~K}$ (MFR $=4 \mathrm{~g} \times 10 \mathrm{~min}^{-1} ; 190{ }^{\circ} \mathrm{C}$ $\times 2.16 \mathrm{~kg}^{-1}$ ) and high-density polyethylene (HDPE) Purell GA $7760 \quad\left(\mathrm{MFR}=18 \mathrm{~g} \times 10 \mathrm{~min}^{-1} ; 190{ }^{\circ} \mathrm{C} \times\right.$ $2.16 \mathrm{~kg}^{-1}$ ) were provided by Basell Orlen Polyolefins and served as polymer matrices. Octakis $(\{n$-octyl $\}$ dimethylsiloxy)octasilsesquioxane (POSS8), octakis( $\{n$-octadecyl $\}$ dimethylsiloxy)octasilsesquioxane (POSS18) and octakis(\{4methyl-hexyl \}dimethylsiloxy)octasilsesquioxane (POSS7b) were synthesized according to the procedure described by Caetano et al. [34]. Chemical structures of POSS8, POSS18 and POSS7b are shown in Fig. 1a-c.

Spectroscopic data of octakis( $\{$ alkyl $\}$ dimethylsiloxy) octasilsesquioxanes (POSS):

Octakis( $\{n$-octyl $\}$ dimethylsiloxy)octasilsesquioxane (POSS8).

${ }^{1} \mathrm{H}$ NMR $\left(\mathrm{CDCl}_{3}, 298 \mathrm{~K}, 300 \mathrm{MHz}\right) \delta[\mathrm{ppm}]=0.11$ $\left(\mathrm{OSiCH}_{3}\right) ; 0.57\left(\mathrm{SiCH}_{2}\right) ; 0.84\left(\mathrm{CH}_{3}\right) ; 1.31\left(\mathrm{CH}_{2}\right)$.

${ }^{13} \mathrm{C} \mathrm{NMR}\left(\mathrm{CDCl}_{3}, 298 \mathrm{~K}, 75.5 \mathrm{MHz}\right) \delta[\mathrm{ppm}]=-0.43$

$\left(\mathrm{OSiCH}_{3}\right) ; 14.1\left(\mathrm{CH}_{3}\right) ; 18.11-34.20\left(\mathrm{CH}_{2}\right)$.

${ }^{29} \mathrm{Si} \mathrm{NMR}\left(\mathrm{CDCl}_{3}, 298 \mathrm{~K}, 59.6 \mathrm{MHz}\right) \delta[\mathrm{ppm}]=12.54$ $\left(\mathrm{OSi}\left(\mathrm{CH}_{3}\right)_{2}\right) ;-108.67$ (SiOSi).

Octakis(\{n-octadecyl $\}$ dimethylsiloxy)octasilsesquioxane (POSS18).

${ }^{1} \mathrm{H}$ NMR $\left(\mathrm{CDCl}_{3}, 298 \mathrm{~K}, 300 \mathrm{MHz}\right) \delta[\mathrm{ppm}]=0.14$ $\left(\mathrm{OSiCH}_{3}\right) ; 0.57\left(\mathrm{SiCH}_{2}\right) ; 0.87\left(\mathrm{CH}_{3}\right) ; 1.26\left(\mathrm{CH}_{2}\right)$.

${ }^{13} \mathrm{C}$ NMR $\left(\mathrm{CDCl}_{3}, 298 \mathrm{~K}, 75.5 \mathrm{MHz}\right) \delta[\mathrm{ppm}]=-0.50$ $\left(\mathrm{OSiCH}_{3}\right) ; 13.62\left(\mathrm{CH}_{3}\right) ; 17.5-33.62\left(\mathrm{CH}_{2}\right)$.

${ }^{29} \mathrm{Si} \mathrm{NMR}\left(\mathrm{CDCl}_{3}, 298 \mathrm{~K}, 59.6 \mathrm{MHz}\right) \delta[\mathrm{ppm}]=12.57$ $\left(\mathrm{OSi}\left(\mathrm{CH}_{3}\right)_{2}\right) ;-108.98(\mathrm{SiOSi})$.

Octakis(\{4-methyl-hexyl $\}$ dimethylsiloxy)octasilsesquioxane (POSS7b).

${ }^{1} \mathrm{H}$ NMR $\left(\mathrm{CDCl}_{3}, 298 \mathrm{~K}, 300 \mathrm{MHz}\right) \delta[\mathrm{ppm}]=0.17$ $\left(\mathrm{OSiCH}_{3}\right) ; 0.60\left(\mathrm{SiCH}_{2}\right) ; 0.86\left(\mathrm{CH}_{3}\right) ; 1.32\left(\mathrm{CH}_{2}\right) ; 1.45$ $(\mathrm{CH})$.

${ }^{13} \mathrm{C} \mathrm{NMR}\left(\mathrm{CDCl}_{3}, 298 \mathrm{~K}, 75.5 \mathrm{MHz}\right) \delta[\mathrm{ppm}]=-0.47$ $\left(\mathrm{OSiCH}_{3}\right) ; 11.51,19.15\left(\mathrm{CH}_{3}\right) ; 22.05,23.41,29.21,41.12$ $\left(\mathrm{CH}_{2}\right), 34.71(\mathrm{CH})$.

${ }^{29} \mathrm{Si} \mathrm{NMR}\left(\mathrm{CDCl}_{3}, 298 \mathrm{~K}, 59.6 \mathrm{MHz}\right) \delta[\mathrm{ppm}]=12.51$ $\left(\mathrm{OSi}\left(\mathrm{CH}_{3}\right)_{2}\right) ;-108.57$ (SiOSi).

\section{Preparation of nanocomposites}

Polyolefin/POSS nanocomposites were obtained by the melt blending method in two-step process: (1) preparation of polyolefin/POSS concentrates and (2) preparation of polyolefin/POSS nanocomposites with predetermined 


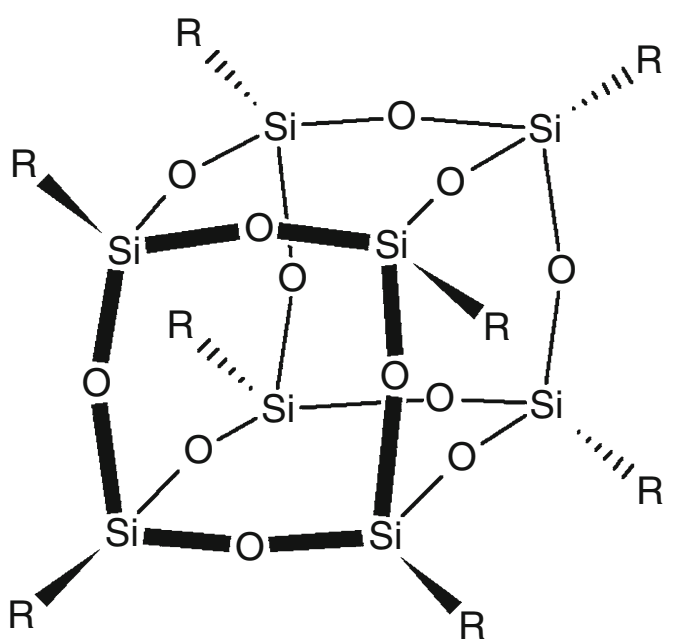

(a)<smiles>[3H]O[Si](C)(C)CCC(C)(C)C</smiles>

(b)<smiles>CC(C)(C)CC(C)(C)[Si](C)(C)O[P]</smiles>

(c)<smiles>CCC(C)CC[Si](C)(C)O[P]</smiles>

Fig. 1 Chemical structures of a POSS8, b POSS18 and c POSS7b nanofillers

concentrations of nanofillers. The first step was carried out in a HAAKE Polylab Reomixer, at 180,170 and $150{ }^{\circ} \mathrm{C}$ for nanocomposites with PP, LDPE and HDPE, respectively. Polyolefin/POSS concentrates contained 10-20 mass $\%$ of POSS nanofillers. The second step was performed in the laboratory twin screw extruder, ZAMAK type IM-15, which was coupled to the laboratory injection molding machine, ZAMAK type IMM-15. Nanocomposites were prepared at $175-195,150-175$ and $155-170{ }^{\circ} \mathrm{C}$ for materials with PP, LDPE and HDPE, respectively. The obtained polyolefin/POSS nanocomposites contained 1, 3, 5 and 10 mass\% of POSS nanofillers. Each sample was marked with the types of the applied polymer matrix and POSS nanofiller, as well as the mass $\%$ content of the POSS nanofiller used. For example, the sample specified as LDPE/ $5 \%$ POSS18 was composed of low-density polyethylene (LDPE) filled with 5 mass\% of the POSS18 nanofiller.

\section{Characterization and measurements}

${ }^{1} \mathrm{H}$ NMR $(300 \mathrm{MHz}),{ }^{13} \mathrm{C}$ NMR $(75 \mathrm{MHz})$ and ${ }^{29} \mathrm{Si}$ NMR (59 MHz) spectra of octasilsesquioxanes were recorded on a Varian XL 300 spectrometer at room temperature, with the use of $\mathrm{CDCl}_{3}$ as a solvent.

Thermal properties of the obtained nanocomposites were studied by the differential scanning calorimetry (DSC) method using a DSC1 Mettler Toledo device. The samples (3-10 mg) were taken from injection molding specimens, and they were put into aluminum pans to undergo three successive runs (heating-cooling-heating) from the room temperature to $170{ }^{\circ} \mathrm{C}$ to erase the previous thermal history of the materials. All tests were performed under nitrogen at the rate of $10{ }^{\circ} \mathrm{C} \times \min ^{-1}$. The presented data were taken from the cooling run (crystallization process) and second heating (melting process) run. The crystallinity degree $\left(X_{\mathrm{c}}\right)$ was calculated from the ratio:

$X_{\mathrm{c}}=\frac{\Delta H_{\mathrm{f}}}{w \cdot \Delta H_{\mathrm{o}}} \cdot 100$

where $\Delta H_{\mathrm{f}}$ is the heat of fusion of the analyzed sample and $\Delta H_{\mathrm{o}}$ is the heat of fusion of the $100 \%$ crystallinity sample (293 $\mathrm{J} \times \mathrm{g}^{-1}$ for HDPE and LDPE [35-37]; $209 \mathrm{~J} \times \mathrm{g}^{-1}$ for PP [38-40]), and $w$ is the mass fraction of polymer in the composite.

Thermogravimetric analyses (TG) were performed on a TG/DSC1 Mettler Toledo device. The samples (3-10 mg) were put into alumina pans and heated under nitrogen or in air from the room temperature to $500{ }^{\circ} \mathrm{C}$ at the rate of $10{ }^{\circ} \mathrm{C} \times \min ^{-1}$. The maximum mass loss rate temperature ( $\left.T_{\max }\right)$ as well as the $T_{5}$ parameters which define the temperature at which $5 \%$ mass losses of samples take place and which characterize the beginning of thermal decomposition was determined for all the materials studied.

The morphological analysis was performed by means of the scanning electron microscopy (SEM), using a Hitachi TM3000 device. The samples were covered with gold before being examined with a microscope. The SEM operating voltage was $15 \mathrm{kV}$.

\section{Results and discussion}

\section{Crystallization and melting behavior studies}

In neat polymers, the homogeneous nucleation process may occur which is controlled mainly by the processing 
conditions and which gives a broad distribution of crystal sizes. In order to provide a better control of the crystallization process, the nucleating agents are introduced. These are substances which could induce the heterogeneous nucleation process, and they control the spherulites formation in crystallizable polymers by creation a large number of spherulites instead of a few large ones [41].

It was found in the literature data that the POSS particles, when introduced into various polyolefin matrices, may act as effective nucleating agents. The structure and the amount of the POSS nanofiller have a great influence on the crystallization behavior and the melting behavior of polyolefin/POSS nanocomposites [20, 21].

In our studies, the influence of POSS nanofillers with long alkyl chain substituents ( $n$-octyl, $n$-octadecyl and 4-methyl-hexyl) attached to the silicon-oxygen $T_{8}$ POSS core on the crystallization behavior and the melting behavior of polyolefin/POSS nanocomposites was determined.

Table 1 lists the values of the crystallinity degree $\left(X_{\mathrm{c}}\right)$, onset, peak and endset crystallization temperatures $\left(T_{\mathrm{co}}\right.$, $T_{\mathrm{cp}}$ and $T_{\mathrm{ce}}$, respectively) as well as onset, peak and endset melting temperatures ( $T_{\mathrm{mo}}, T_{\mathrm{mp}}$ and $T_{\mathrm{me}}$, respectively) for neat polyolefins and for polyolefin/POSS nanocomposites, as evaluated by differential scanning calorimetry (DSC).

The DSC parameters were found to be depended on the kind of the polymer matrix applied (PP, LDPE, HDPE) as well as on the kind of the POSS nanofiller (POSS8, POSS18, POSS7b) and its mass\% content in the nanocomposite (1-10 mass\%).

The incorporation of POSS particles into polyolefin matrices resulted in the increase of the crystallinity degree $\left(X_{\mathrm{c}}\right)$ values for the nanocomposites. Moreover, the increasing POSS mass $\%$ contents in polyolefin/POSS nanocomposites caused a further increase in the $X_{\mathrm{c}}$ values. These results indicate that POSS particles may act as nucleating agents for the crystallization process of polyethylene or polypropylene matrices [20, 25, 31].

It should be noted that in many literature reports the crystallinity degree values for POSS-containing nanocomposites are calculated without taking account of the share of POSS nanofillers in the composite materials [21, 33, 42-45]. In this case, the decrease in $X_{\mathrm{c}}$ values for the studied nanocomposites was observed, in comparison with neat polymer, irrespective of the POSS nanofiller kind and type of polyolefin matrix used (data not shown).

In the case of PP and LDPE nanocomposites containing $n$-alkyl-substituted POSS nanofillers, incorporation of POSS particles into the polymeric matrix caused a slight increase in $T_{\mathrm{cp}}$ values as compared to neat matrices. However, the observed changes often fell within the limits of experimental error (up to 0.4 and $1.6{ }^{\circ} \mathrm{C}$, respectively), irrespective of the lengths of $n$-alkyl substituents on the silicon-oxygen core of POSS (Table 1, items 1-18). The values of $T_{\text {co }}$ for PP/POSS nanocomposites were generally slightly decreased with the increasing POSS mass\% content (Table 1, items 1-9), in relation to neat PP and irrespective of the kind of the POSS nanofiller applied (POSS8 or POSS18). The values of $T_{\mathrm{co}}$ for LDPE/POSS nanocomposites were slightly shifted toward higher temperatures (Table 1, items 10-18), which means that the POSS particles could more effectively accelerate crystallization of LDPE, in comparison with PP. The changes of $T_{\text {ce }}$ values for PP/POSS and for LDPE/POSS nanocomposites were less systematic, but they increased generally with the increasing POSS amount in the nanocomposites (Table 1, items 1-18) which was especially visible for the POSScontaining LDPE nanocomposites (Table 1, items 10-18).

It should be noted that the increasing mass $\%$ content of POSS in PP and in LDPE nanocomposites resulted in the narrowing of the exothermic peak corresponding to the polymer crystallization process (Fig. 2a, b). These results suggested that the crystallization process of those polymers started later in the presence of POSS particles but it run much faster as compared to neat PP or LDPE. This effect clearly indicated that POSS particles acted as effective nucleating agents in PP/POSS and LDPE/POSS nanocomposites and that they can accelerate the polymer crystallization process.

Interestingly, the SEM analysis revealed that in the case of PP/POSS nanocomposites the spherulitic morphology was visible (Fig. 3b, c) while no specific morphological features were observed for neat PP (Fig. 3a). No POSS aggregates were demonstrated which suggests good dispersion of POSS in the polypropylene matrix [20]. Hence, it may be assumed that POSS subnanometric aggregates may be located in the center of each spherulite, acting probably as a growth center. In turn, no distinct changes in morphology were observed for LDPE/POSS nanocomposites versus neat LDPE (data not shown).

For HDPE/POSS nanocomposites, $T_{\mathrm{cp}}$ values were only slightly increased regardless of the amount of the POSS nanofiller (Table 1, items 19-31). Furthermore, $T_{\text {co }}$ values were almost unchanged as compared to the neat HDPE matrix. The changes in $T_{\text {ce }}$ values were not systematic, but they were generally close to the temperature obtained for neat polymer. After that, the narrowing of the exothermic peak which corresponds to the polymer crystallization process was not observed in the case of HDPE/POSS nanocomposites (Fig. 2c). Hence, any clear indication of the nucleating effect of the POSS is difficult for these nanocomposites. Firstly, the effectiveness of POSS as nucleating agents in the HDPE matrix is much lower than for PP or LDPE. Secondly, HDPE is characterized by much higher values of the crystallinity degree in comparison with those for PP or LDPE, and thus, it is difficult to improve the HDPE crystallization process. 
Table 1 Thermal parameters of neat matrices and polyolefin/POSS nanocomposites obtained during DSC investigations

\begin{tabular}{|c|c|c|c|c|c|c|c|c|}
\hline \multirow[t]{2}{*}{ Item } & \multirow[t]{2}{*}{ Sample } & \multirow[t]{2}{*}{$X_{\mathrm{c}} / \%$} & \multicolumn{3}{|c|}{ Cooling } & \multicolumn{3}{|c|}{ 2nd heating } \\
\hline & & & $T_{\mathrm{co}} /{ }^{\circ} \mathrm{C}$ & $T_{\mathrm{cp}} /{ }^{\circ} \mathrm{C}$ & $T_{\mathrm{ce}} /{ }^{\circ} \mathrm{C}$ & $T_{\mathrm{mo}} /{ }^{\circ} \mathrm{C}$ & $T_{\mathrm{mp}} /{ }^{\circ} \mathrm{C}$ & $T_{\mathrm{me}} /{ }^{\circ} \mathrm{C}$ \\
\hline 1. & $\mathrm{PP}$ & 33.54 & 118.0 & 113.8 & 108.2 & 153.7 & 163.2 & 170.4 \\
\hline 2. & PP/1 \%POSS8 & 33.53 & 117.5 & 113.9 & 108.6 & 153.7 & 162.3 & 169.8 \\
\hline 3. & $\mathrm{PP} / 3 \% \mathrm{POSS} 8$ & 33.52 & 117.3 & 114.2 & 110.1 & 154.1 & 160.1 & 168.7 \\
\hline 4. & $\mathrm{PP} / 5 \% \mathrm{POSS} 8$ & 34.26 & 117.0 & 114.0 & 107.5 & 152.3 & 163.7 & 170.5 \\
\hline 5. & PP/10 \%POSS8 & 33.61 & 117.2 & 114.3 & 110.1 & 152.7 & 160.4 & 168.4 \\
\hline 6. & PP/1 \%POSS18 & 33.75 & 117.4 & 113.4 & 107.6 & 153.4 & 163.1 & 170.5 \\
\hline 7. & PP/3 \%POSS18 & 34.27 & 117.1 & 113.9 & 108.1 & 153.5 & 163.1 & 170.2 \\
\hline 8. & PP/5 \%POSS18 & 33.98 & 116.9 & 113.7 & 108.7 & 153.2 & 161.9 & 169.4 \\
\hline 9. & PP/10 \%POSS18 & 34.57 & 117.1 & 114.2 & 109.1 & 152.5 & 161.7 & 169.0 \\
\hline 10. & LDPE & 43.83 & 102.0 & 99.1 & 92.9 & 105.2 & 114.1 & 118.2 \\
\hline 11. & LDPE/1 \%POSS8 & 42.03 & 102.3 & 100.1 & 94.5 & 106.1 & 113.0 & 117.3 \\
\hline 12. & LDPE/3 \%POSS 8 & 43.59 & 102.5 & 100.3 & 94.3 & 105.9 & 113.2 & 117.3 \\
\hline 13. & LDPE/5 \%POSS8 & 44.08 & 102.5 & 100.7 & 95.2 & 106.3 & 112.8 & 116.6 \\
\hline 14. & LDPE/10 \%POSS8 & 47.96 & 102.6 & 100.7 & 95.8 & 106.8 & 112.8 & 116.4 \\
\hline 15. & LDPE/1 \%POSS18 & 42.95 & 102.5 & 100.2 & 94.2 & 105.9 & 113.3 & 117.5 \\
\hline 16. & LDPE/3 \%POSS18 & 42.68 & 102.4 & 100.1 & 93.1 & 105.7 & 113.2 & 118.1 \\
\hline 17. & LDPE/5 \%POSS18 & 41.79 & 102.6 & 100.3 & 94.2 & 106.0 & 113.2 & 117.5 \\
\hline 18. & LDPE/10 \%POSS18 & 45.32 & 102.4 & 100.4 & 94.9 & 106.6 & 113.2 & 117.0 \\
\hline 19. & HDPE & 74.26 & 120.3 & 118.4 & 111.2 & 124.8 & 132.1 & 137.9 \\
\hline 20 & HDPE/1 \%POSS8 & 75.02 & 120.5 & 118.4 & 111.6 & 124.6 & 132.8 & 137.6 \\
\hline 21. & HDPE/3 \%POSS 8 & 74.81 & 120.7 & 118.8 & 111.1 & 124.4 & 132.8 & 138.1 \\
\hline 22. & HDPE/5 \%POSS8 & 76.10 & 120.9 & 118.8 & 110.5 & 123.9 & 133.3 & 138.7 \\
\hline 23. & HDPE/10 \%POSS8 & 77.96 & 120.1 & 118.4 & 111.5 & 124.7 & 132.4 & 136.9 \\
\hline 24. & HDPE/1 \%POSS18 & 75.81 & 120.6 & 118.7 & 112.5 & 124.9 & 131.9 & 136.6 \\
\hline 25. & HDPE/3 \%POSS18 & 75.58 & 120.7 & 118.7 & 111.0 & 124.6 & 132.3 & 137.9 \\
\hline 26. & HDPE/5 \%POSS18 & 73.85 & 120.5 & 118.3 & 110.4 & 123.9 & 133.3 & 138.9 \\
\hline 27. & HDPE/10 \%POSS18 & 77.92 & 120.0 & 117.9 & 109.7 & 123.7 & 132.9 & 138.6 \\
\hline 28. & HDPE/1 \%POSS7b & 74.36 & 120.2 & 118.5 & 112.8 & 124.4 & 132.1 & 136.2 \\
\hline 29. & HDPE/3 \%POSS7b & 73.68 & 120.3 & 118.4 & 110.2 & 124.2 & 132.8 & 138.6 \\
\hline 30. & HDPE/5 \%POSS7b & 71.96 & 120.3 & 118.5 & 111.1 & 124.7 & 131.9 & 137.5 \\
\hline 31. & HDPE/10 \%POSS7b & 77.04 & 120.3 & 118.8 & 112.4 & 125.0 & 131.7 & 136.4 \\
\hline
\end{tabular}

Adding nucleating agents into polymer matrix may affect not only the crystallization behavior but also the polymer melting process. In many cases, lower melting temperatures were observed for composites, in comparison with neat polymers. This phenomenon can be related to several factors and some of them are associated with the presence of nucleating agents which promote the formation of many nucleating points in the polymeric material [46]. In this case, each crystal has a small space available for it during the crystal growth. Thus, smaller and more imperfect crystals are created in comparison with those for neat polyolefin matrices, resulting in the decrease in melting temperature for composite materials [46].
The increasing POSS mass\% content in the PP/POSS nanocomposites resulted in a slight decrease in $T_{\mathrm{mp}}$ values in comparison with the neat PP matrix (Table 1, items 1-9), but there were no systematic changes in $T_{\text {mo }}$ values. In turn, $T_{\mathrm{me}}$ values decreased at increasing POSS mass\% contents in the PP matrix. In the case of LDPE/POSS nanocomposites, $T_{\mathrm{mp}}$ values were slightly lower for the increasing amount of POSS nanofiller in the LDPE matrix (Table 1, items 10-18). Simultaneously, the $T_{\mathrm{mo}}$ and $T_{\mathrm{me}}$ values were increased and decreased, respectively, with the increasing mass\% content of the POSS nanofiller. The endothermic peak on DSC curves associated with melting process in PP/POSS and LDPE/POSS nanocomposites was 


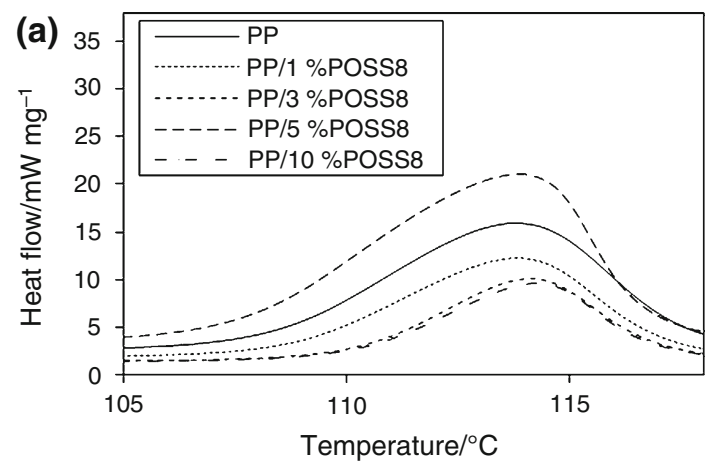

(b)

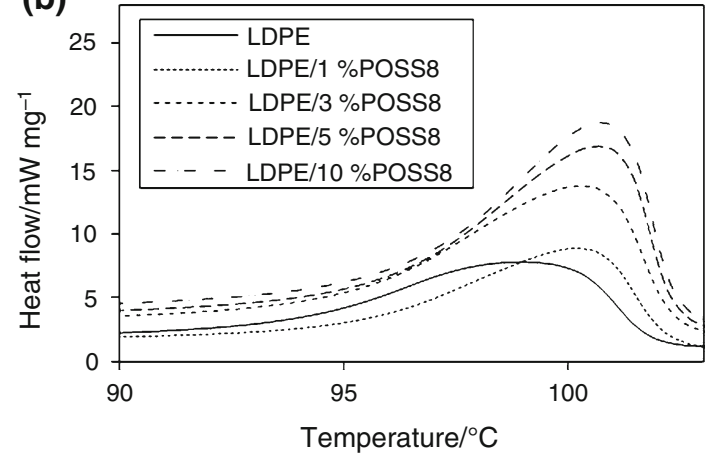

(c)

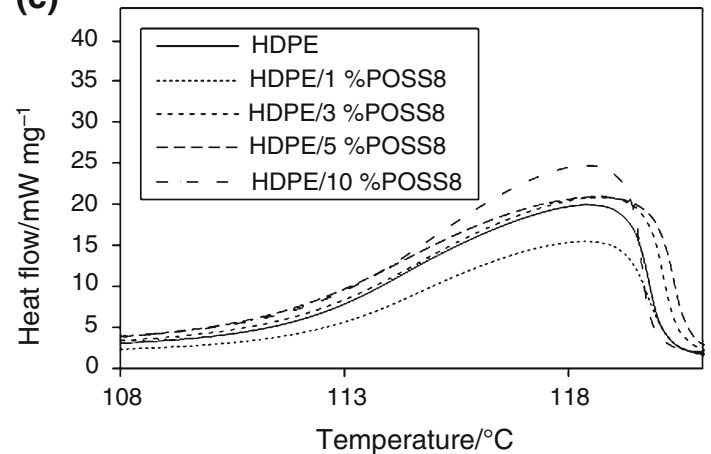

Fig. 2 DSC curves of a neat PP and PP/POSS8 nanocomposites, b neat LDPE and LDPE/POSS8 nanocomposites as well as c neat HDPE and HDPE/POSS8 nanocomposites

narrowed in comparison with the peak for neat PP or LDPE matrices. It is clear that the melting behavior of those polymers was unsettled by incorporation of POSS particles which acted as nucleating agents.

In the case of HDPE/POSS nanocomposites, some changes in the melting temperatures values were observed in comparison with neat HDPE although the crystallization temperatures did not vary greatly. The increasing mass\% content of POSS 8 and POSS18 in the HDPE matrix resulted generally in the growth of $T_{\mathrm{mp}}$ values (Table 1, items 19-27). In turn, incorporation of POSS7b caused a slight decrease in those temperatures (Table 1, items 28-31). In the case of all analyzed HDPE/POSS nanocomposites, $T_{\text {mo }}$ and $T_{\mathrm{me}}$ values were almost unchanged in comparison with the neat HDPE matrix. The melting temperatures of polymer materials are known to be strongly correlated with the
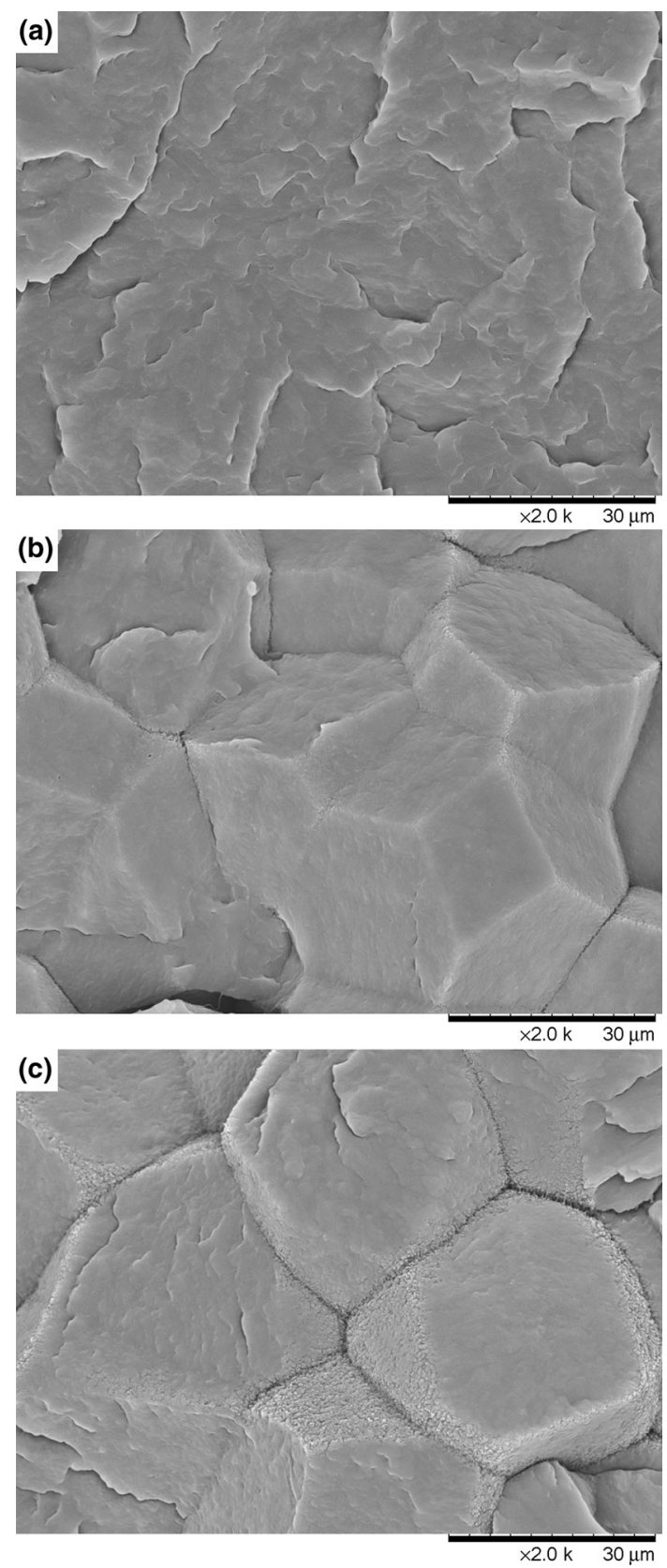

Fig. 3 SEM micrographs of a neat PP, b PP/10 \%POSS8 and c PP/ $10 \%$ POSS18 nanocomposites

structures of those materials and with the sizes and perfection of crystallites in a polymer [47]. Because of that, the changes of $T_{\mathrm{mp}}$ values may suggest that the polymer chains are more orderly arranged in the presence of POSS 8 or POSS18 molecules than in neat HDPE. It may thus be assumed that the POSS 8 and POSS18 molecules not only accelerate the HDPE crystallization process but they also give rise to the order of polyethylene chains.

It can be concluded that the structure of alkyl substituents attached to the silicon-oxygen $T_{8}$ POSS core had a substantial influence on thermal properties of the POSS- 
containing polyolefin nanocomposites obtained. In the case of nanocomposites which were filled with the POSS8 with $n$-octyl chains as substituents, more significant changes in the crystallization temperature and melting temperature values were observed than for the nanocomposites contained POSS18 and which possessed n-octadecyl substituents on the POSS core. Therefore, POSS molecules with shorter alkyl chain substituents could be considered as more effective nucleating agents than those with longer alkyl chain groups. These results are consistent with those presented in papers $[20-22,25,29,30]$ where it is reported that the lengthening of alkyl substituents (from methyl to iso-octyl) attached to the $T_{8}$ POSS core decreased effectiveness of POSS particles as nucleating agents.

In turn, the presence of branched 4-methyl-hexyl substituents in POSS (POSS7b) insignificantly affects the crystallization and melting behavior of nanocomposites obtained, in comparison with the nanocomposite materials with POSS molecules which contain long unbranched $n$ alkyl chains. It should be noted that Frone et al. [26, 27] showed that octakis(dimethylsiloxy)octasilsesquioxanes bearing branched alkyl substituents such as 3,3-dimethylpropyl, 3,3-dimethyl-butyl and 3,3-dimethyl-pentyl may slightly enhance the crystallization behavior of LDPE/ POSS nanocomposites.

\section{Thermal stability studies}

The incorporation of the thermally robust POSS moiety significantly affects the polyolefin thermal properties, contributing toward greater thermal stability of the polymer matrix $[20,23,24,26,27,30,43,45]$. This influence is visible, especially in the case of thermo-oxidative behavior of polymer.

Thermo-oxidative degradation of POSS leads to the formation of a silica-like residue [26, 27]. POSS nanofillers tend to accumulate on the material surface during heating, and they form a ceramic layer that acts as a protective barrier which significantly reduces flow of heat and gas into nanocomposite material $[20,24,48]$. Thus, the significant increase in thermal stability of POSS-containing polyolefin nanocomposites is observed especially in terms of higher mass loss temperatures [20, 24, 26, 27, 30, 42, 43, $45,48]$. However, it should be emphasized that the extent of improvement in thermal stability for such composites depends on the type of the polymer matrix and on the structure and content of the POSS filler.

In our studies, the thermogravimetric analysis (TG) was performed to examine the thermal degradation behavior of neat POSS compounds, neat polyolefin matrices and the polyolefin/POSS nanocomposites obtained.

The investigation of the thermal stability of neat POSS was important to understand the influence of those nanofillers on thermal stability of the POSS-containing polyolefin nanocomposites obtained. The thermogravimetric analysis for neat POSS compounds performed under nitrogen revealed that thermal stability of POSS was strongly depended on the structures of the alkyl substituents on the $T_{8}$ POSS core. Figure $4 \mathrm{a}$ shows the TG curves under nitrogen for POSS8, POSS18 and POSS7b. Thermal stability was observed to increase in order: POSS7b $<$ POSS $8<$ POSS 18 , as regards the maximum mass loss rate temperature $\left(T_{\max }\right)$ which ranges from $461.9{ }^{\circ} \mathrm{C}$ for POSS7b and $485.0{ }^{\circ} \mathrm{C}$ for POSS8 to $491.5{ }^{\circ} \mathrm{C}$ for POSS18. The mass loss takes place in a single step.

Moreover, it was found that the lengthening of the alkyl chain substituents in the POSS molecule clearly increased the values of the $T_{5}$ parameter. The values of $T_{5}$ were: 354.2, 411.4 and $439.9{ }^{\circ} \mathrm{C}$ for POSS7b, POSS8 and POSS18, respectively. It should be noted that the value of $T_{5}$ for POSS18 (containing $n$-octadecyl substituents) was higher by almost $30{ }^{\circ} \mathrm{C}$ in comparison with that for POSS 8 with ( $n$-octyl substituents on silicon-oxygen core). Thus, it could be concluded that the increase in the alkyl chain length of the substituent at the silicon-oxygen cage improved thermal stability of the POSS compound. In turn, in the case of POSS7b with branched alkyl substituents, the decreased value of $T_{5}$ by almost $60{ }^{\circ} \mathrm{C}$ was observed in comparison with POSS8. Similar results were obtained by Fina et al. [10] who revealed that POSS molecules with
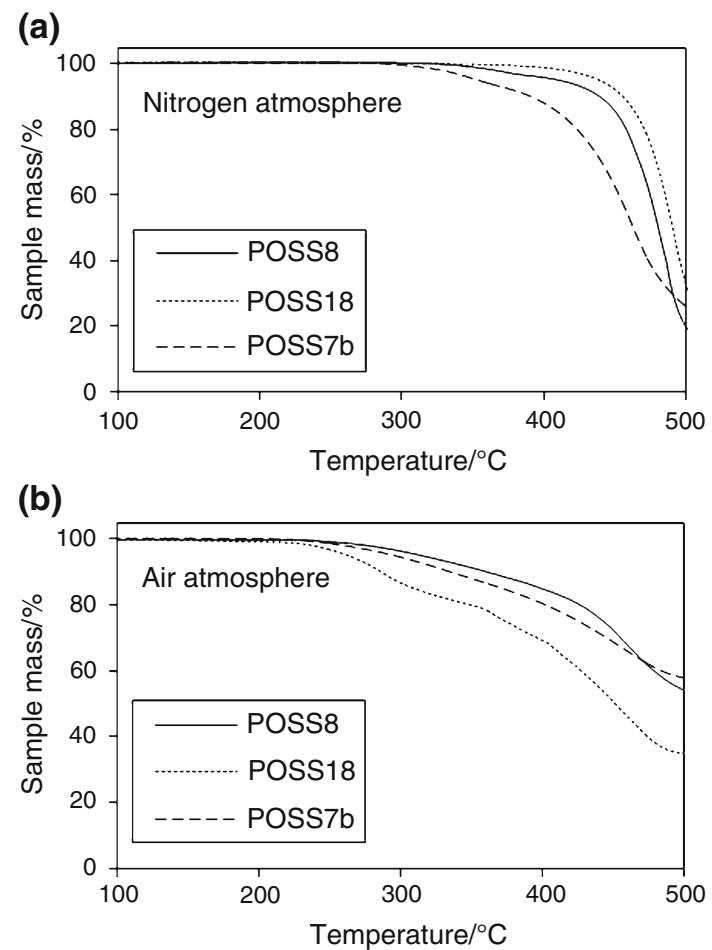

Fig. 4 TG curves of neat POSS compounds a under nitrogen and $\mathbf{b}$ in air atmosphere 

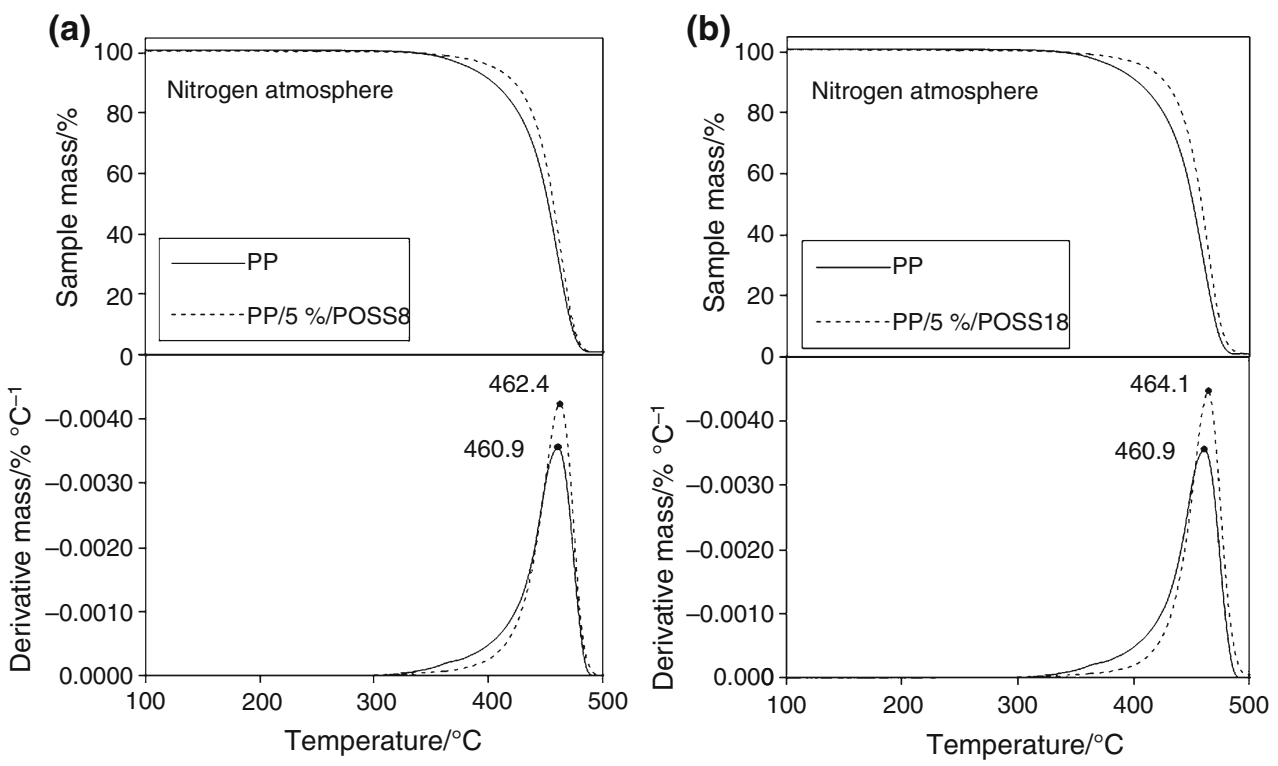

Fig. 5 TG curves of a neat PP and PP/5 \%POSS8 nanocomposite, and $\mathbf{b}$ neat PP and PP/5 \%POSS18 nanocomposite under nitrogen

methyl substituents were less thermal stable than the POSS structures which contained iso-butyl or iso-octyl groups. The POSS molecules which contain short alkyl chain groups on the silicon-oxygen core undergo almost complete sublimation, while those with longer alkyl chain substituents evaporate above the POSS melting temperatures [10].

In the case of POSS-containing polyolefin nanocomposites, it was observed that their thermal stability strongly depended on the structure of the POSS nanofiller as well as on dispersion of the POSS particles in the polyolefin matrices.

As regards PP/POSS nanocomposites, incorporation of the POSS particles clearly enhanced thermal stability of those materials under nitrogen. The presence of 5 mass $\%$ of POSS 8 and POSS18 nanofillers significantly increased the values of $T_{5}$, by 22 and $28{ }^{\circ} \mathrm{C}$, respectively $\left(T_{5}=405.5\right.$ and $411.2{ }^{\circ} \mathrm{C}$ for PP/POSS8 and PP/POSS18, respectively) in comparison with the neat PP matrix: $T_{5}=383.7{ }^{\circ} \mathrm{C}$. However, the values of $T_{5}$ for the PP/POSS nanocomposites were lower than those for neat POSS. The values of the maximum mass loss rate temperature for the POSS-containing PP nanocomposites did not vary considerably with the length of the alkyl substituent on the POSS core ( $T_{\max }=462.4$ and $464.1{ }^{\circ} \mathrm{C}$ for PP/5 \%POSS 8 and PP/ $5 \%$ POSS18, respectively), but they were slightly higher in comparison with $T_{\max }$ for neat PP: $T_{\max }=460.9{ }^{\circ} \mathrm{C}$ (Fig. 5a, b) and lower than $T_{\max }$ for neat POSS8 and POSS18 nanofillers.

In the case of LDPE/POSS nanocomposites, addition of POSS nanofillers into the LDPE matrix also enhanced thermal stability of the composite materials under nitrogen.
The values of $T_{5}$ were improved by 7 and $9{ }^{\circ} \mathrm{C}$ for LDPE/ $5 \%$ POSS8 and LDPE/5\%POSS18 nanocomposite ( $T_{5}=437.1$ and $438.8^{\circ} \mathrm{C}$, respectively) in comparison with the neat LDPE matrix $\left(T_{5}=429.7^{\circ} \mathrm{C}\right)$. It should be distinguished that incorporation of 5 mass $\%$ of POSS8 into LDPE caused the increase in the value of $T_{5}$ as compared to neat LDPE as well as with the neat POSS8 compound $\left(T_{5}=411.4{ }^{\circ} \mathrm{C}\right)$. LDPE in the composite was degraded with the maximum rate temperature totally coincident $\left(T_{\max }=477.1\right.$ and $477.2^{\circ} \mathrm{C}$ for LDPE $/ 5 \%$ POSS 8 and LDPE/5 \%POSS18 nanocomposites, respectively) with that of neat LDPE $\left(T_{\max }=478.9^{\circ} \mathrm{C}\right)($ Fig. 6a, b).

It is interesting that thermogravimetric experiments for HDPE/POSS nanocomposites conducted under nitrogen revealed that incorporation of 5 mass $\%$ of POSS8 and POSS18 nanofillers into HDPE resulted in a slight decrease in the values of $T_{5}\left(T_{5}=453.6{ }^{\circ} \mathrm{C}\right.$ for HDPE/POSS 8 and $455.5{ }^{\circ} \mathrm{C}$ for HDPE/POSS18, respectively) in comparison with the neat matrix $\left(T_{5}=458.5^{\circ} \mathrm{C}\right)$. Moreover, addition of the POSS7b nanofiller to HDPE caused the most significant decrease in the value of $T_{5}$, by $17{ }^{\circ} \mathrm{C}\left(T_{5}=\right.$ $441.6{ }^{\circ} \mathrm{C}$ ) in comparison with the neat HDPE matrix. Declining thermal stability of the HDPE/POSS nanocomposites in the presence of the POSS with branched alkyl substituents on the silicon-oxygen core may be the result of low thermal stability of the neat POSS7b compound.

Degradation of polymeric nanocomposites is generally studied in the inert atmosphere. However, the degradation tests in air provide more practical information about the behavior of those materials at higher temperatures.

Thermal degradation of neat POSS compounds in the presence of air is different than degradation under nitrogen. 

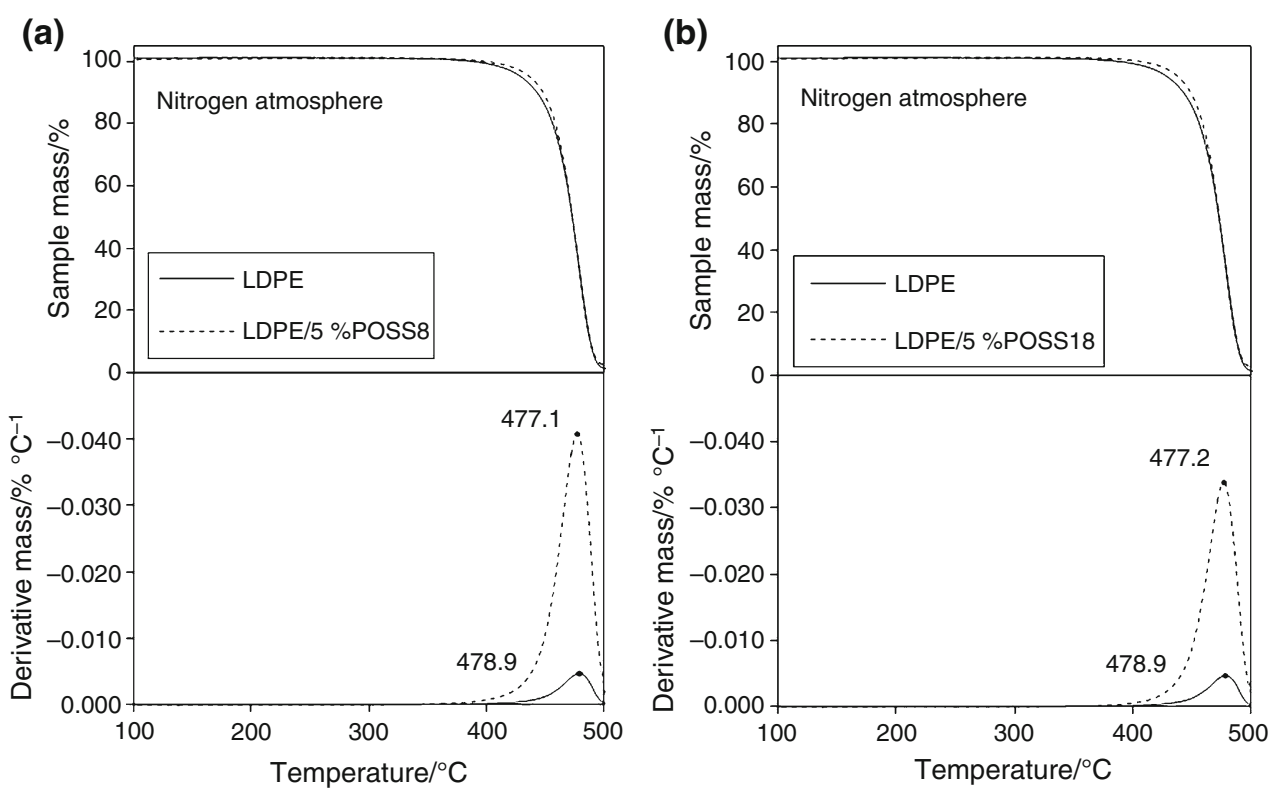

Fig. 6 TG curves of a neat LDPE and LDPE/5 \%POSS8 nanocomposite, and b neat LDPE and LDPE/5 \%POSS18 nanocomposite under nitrogen

The evaporation and oxidation phenomena compete with each other during thermal degradation of POSS compounds with long alkyl chain substituents which leads to the formation of a thermally stable residue. The oxidation mechanism combines peroxidation of the alkyl chains and subsequent fragmentation through classical radical pathways [10]. For this reason, the values of $T_{5}$ for the neat POSS8, POSS18 and POSS7b compounds were much lower in comparison with the appropriate parameters obtained from the tests under nitrogen. Interestingly, lengthening of the alkyl chains in substituents on the $T_{8}$ POSS core from $n$-octyl (POSS8) to $n$-octadecyl (POSS18) caused a substantial decrease in the value of $T_{5}$ by $51.9{ }^{\circ} \mathrm{C}$ $\left(T_{5}=315.0\right.$ and $263.1^{\circ} \mathrm{C}$ for POSS8 and POSS18, respectively). In turn, branching of alkyl substituents attached to the POSS core in the case of POSS7b also decreased the value of $T_{5}$ by $19.2{ }^{\circ} \mathrm{C}\left(T_{5}=295.8^{\circ} \mathrm{C}\right)$ against POSS8. Thus, it could be concluded that thermal stability in air of neat POSS compounds increased in the order: POSS $18<$ POSS7b $<$ POSS8. It is interesting that $T_{\max }$ was $451.8^{\circ} \mathrm{C}$ for POSS18, $454.2{ }^{\circ} \mathrm{C}$ for POSS 8 and $459.3^{\circ} \mathrm{C}$ in the case of POSS7b (Fig. $4 \mathrm{~b}$ ).

The TG studies for neat PP, LDPE and HDPE performed in air revealed a decrease in the values of $T_{5}$ and $T_{\max }$ values, in comparison with the results obtained under nitrogen atmosphere. This may be a result of the oxidizing action of oxygen molecules on polymer chains which considerably accelerates the polymer degradation processes $[49,50]$.

Incorporation of POSS nanofillers into the PP matrix was found generally to improve thermal stability of the nanocomposites obtained, regardless of the kind of the POSS applied, in comparison with neat PP. Higher $\mathrm{T}_{5}$ values were obtained even when 1 mass $\%$ of POSS18 was introduced into the PP matrix $\left(T_{5}=295.5\right.$ and $289.1{ }^{\circ} \mathrm{C}$ for PP/POSS18 nanocomposite and neat PP, respectively). It should be noted that the increasing POSS18 mass\% content for the PP/POSS18 nanocomposites (from 1 to 5 mass $\%$ ) increased this parameter even further $\left(T_{5}=299.8^{\circ} \mathrm{C}\right)$. On the other hand, when 1 mass\% of POSS8 was used as nanofiller, smaller changes were observed in the values of $T_{5}\left(292.4{ }^{\circ} \mathrm{C}\right)$ in comparison with the neat matrix. Moreover, the increase in the content of POSS8 to 5 mass $\%$ decreased the values of $T_{5}\left(285.8{ }^{\circ} \mathrm{C}\right)$. Furthermore, for POSS18-containing PP nanocomposites (Fig. 7), higher maximum mass loss rate temperatures $\left(T_{\max }\right)$ were observed which varied from 372.0 to $394.3{ }^{\circ} \mathrm{C}$ for PP/1 \%POSS18 and PP/5 \%POSS18 nanocomposites, respectively, in comparison with analogous nanocomposites with POSS8 $\left(T_{\max }=368.7\right.$ and $365.1^{\circ} \mathrm{C}$, respectively) as well as with neat $\mathrm{PP}\left(T_{\max }=366.9^{\circ} \mathrm{C}\right)$.

In the case of LDPE/POSS nanocomposites, addition of POSS nanofillers into the LDPE matrix had also a significant impact on thermal stability of the composite materials obtained. The increasing mass\% content of POSS18 in LDPE nanocomposites increased the value of $T_{5}$ up to $62{ }^{\circ} \mathrm{C} \quad\left(T_{5}=345.8{ }^{\circ} \mathrm{C}\right.$ for $\mathrm{LDPE} / 1 \% \mathrm{POSS} 18$ and $396.5{ }^{\circ} \mathrm{C}$ for $\mathrm{PP} / 5 \% \mathrm{POSS} 18$ nanocomposites, respectively), in comparison with neat $\operatorname{LDPE}\left(T_{5}=334.1^{\circ} \mathrm{C}\right)$. For LDPE/POSS8 nanocomposites, the highest values of $T_{5}$ were received for LDPE/1 \%POSS8 nanocomposite $\left(T_{5}\right.$ $=373.6^{\circ} \mathrm{C}$ ). Any further increase in the POSS8 content 
Fig. 7 TG curves of a neat PP and PP/POSS8 nanocomposites, and $\mathbf{b}$ neat PP and PP/POSS18 nanocomposites in air
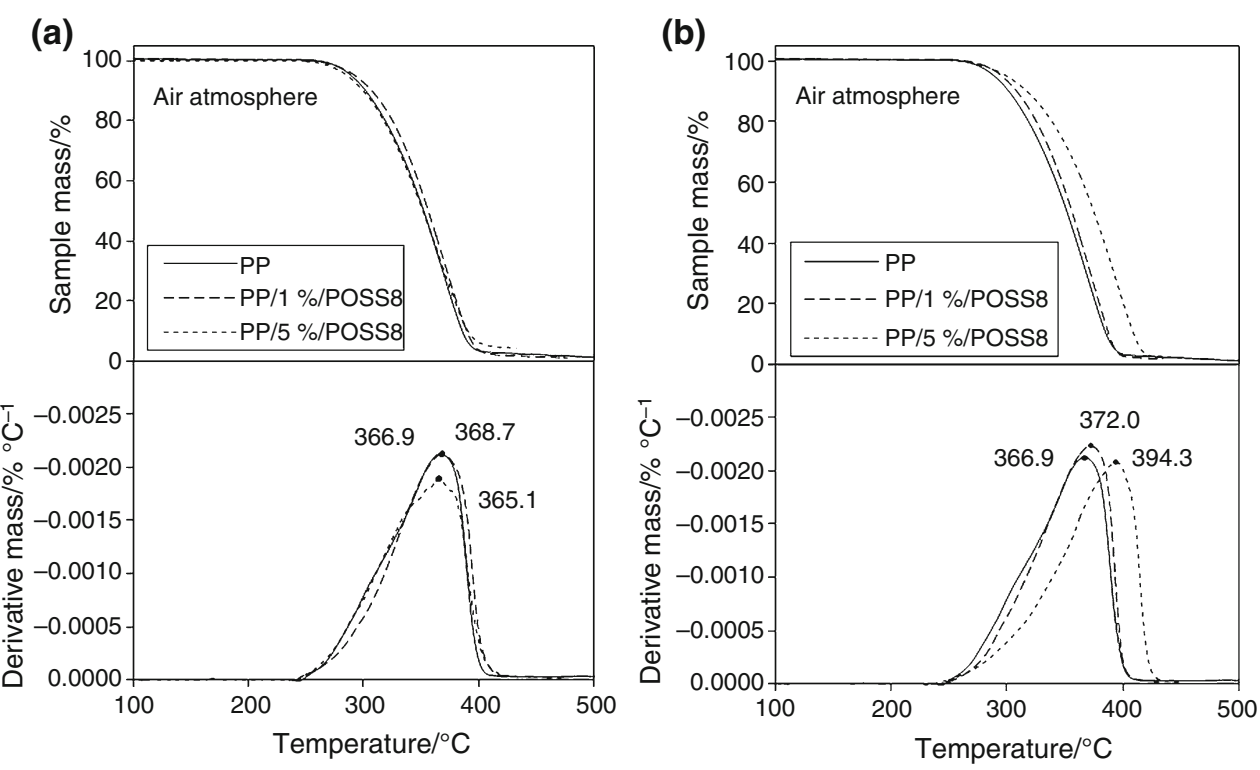

resulted in a significant decrease in the values of this parameter $\left(T_{5}=315.4^{\circ} \mathrm{C}\right)$.

Addition of POSS nanofillers into the LDPE matrix improved also the value of $T_{\max }$, in comparison with neat LDPE $\left(T_{\max }=434.7^{\circ} \mathrm{C}\right)$. When the content of POSS was 1 mass $\%$, a slightly higher value of $T_{\max }$ was obtained for LDPE/POSS8 nanocomposites $\left(T_{\max }=445.0^{\circ} \mathrm{C}\right)$, than with LDPE/POSS18 nanocomposites $\left(T_{\max }=442.6^{\circ} \mathrm{C}\right)$. At higher nanofiller contents, however, the value of $T_{\max }$ was higher for LDPE/5 \%POSS18 $\left(T_{\max }=452.2^{\circ} \mathrm{C}\right)$, against the LDPE/5 \%POSS8 nanocomposite $\left(T_{\max }=427.5^{\circ} \mathrm{C}\right)$.

Incorporation of POSS particles into the HDPE matrix also improved thermal stability of the nanocomposite materials obtained. In the case of HDPE nanocomposites filled with POSS containing linear alkyl substituents at the silicon-oxygen POSS core (POSS8 and POSS18), a substantial increase in the values of $T_{5}$ was observed, in comparison with the neat matrix $\left(T_{5}=318.8{ }^{\circ} \mathrm{C}\right)$, when nanofillers were used even at the amount of 1 mass $\%\left(T_{5}\right.$ $=349.3$ and $382.8^{\circ} \mathrm{C}$ for HDPE/POSS8 and HDPE/ POSS18 nanocomposites, respectively). As regards HDPE/ POSS8 nanocomposites, the increasing mass $\%$ content of the nanofiller, from 1 to 5 mass $\%$, decreased the values of that parameter $\left(T_{5}=326.8^{\circ} \mathrm{C}\right)$. After incorporation of the POSS18 nanofiller into the HDPE matrix, the value of $T_{5}$ parameter was decreasing (from $382.8{ }^{\circ} \mathrm{C}$ to $336.9^{\circ} \mathrm{C}$ ) with the increasing content of POSS from 1 to 5 mass\%. In turn, addition of POSS7b into HDPE resulted in the gradual increase in values of the $T_{5}$ values with the increasing mass $\%$ content of POSS $\left(T_{5}=332.1\right.$ and $344.2{ }^{\circ} \mathrm{C}$ for HDPE/1 \%POSS7b and HDPE/5 \%POSS7b nanocomposites, respectively), and the values of those parameters were higher in comparison with those for neat HDPE.
The values of the maximum mass loss rate temperatures ( $\left.T_{\max }\right)$ were depended on the kind of the POSS nanofillers applied and their contents in HDPE nanocomposites. At 1 mass $\%$ of POSS, the $T_{\max }$ values for nanocomposites increased in the order: HDPE/POSS7b $\left(388.4^{\circ} \mathrm{C}\right)<\mathrm{HDPE} /$ POSS18 $\left(459.0^{\circ} \mathrm{C}\right)<$ HDPE/POSS8 $\left(462.2^{\circ} \mathrm{C}\right)$, when $T_{\max }=452.5^{\circ} \mathrm{C}$ for neat HDPE. In the case of nanocomposites containing 5 mass $\%$ of POSS nanofillers, the values of $T_{\max }$ varied as follows: HDPE/POSS8 $\left(453.1^{\circ} \mathrm{C}\right)<$ HDPE/POSS7b $\left(463.5^{\circ} \mathrm{C}\right)<$ HDPE/POSS18 $\left(469.2^{\circ} \mathrm{C}\right)$.

Summarizing the results from TG performed under nitrogen and in air, different POSS structures had different impacts on thermal stability of POSS-containing polyolefin nanocomposites.

TG under nitrogen revealed that the nanocomposites filled with POSS18 which contained n-octadecyl substituents exhibited higher thermal stability than neat polymer, irrespective of the kind of the polyolefin matrices applied. Yet, incorporation of POSS8 with $n$-octyl substituents improved thermal stability of nanocomposite materials less significantly in comparison with nanocomposites with POSS18. High thermal stability of nanocomposites with $n$-octadecylsubstituted POSS can be explained by high thermal stability of neat POSS18, which was characterized by the highest values of $T_{5}$ and $T_{\max }$ among the POSS nanofillers studied. In turn, application of POSS7b with branched alkyl substituents on the POSS core into the HDPE matrix decreased thermal stability of nanocomposites in comparison with nanocomposites with POSS containing unbranched alkyl substituents on the POSS core as well as with neat polymer, probably because of lower thermal stability of neat POSS7b.

The atmospheric TG results showed that, in the case of polyolefin nanocomposites containing POSS with linear 
alkyl substituents, application of POSS with longer alkyl chain substituents (POSS18) can clearly enhance thermal stability of polyolefin/POSS nanocomposites, while incorporation of POSS with shorter alkyl chain substituents on the silicon-oxygen cage (POSS8) caused less significant changes. It is interesting that POSS18-containing polyolefin nanocomposites are more thermally stable in air, than nanocomposites with POSS8 particles, despite the fact that neat POSS18 is characterized by lower thermal stability than POSS8. It could be supposed that the POSS particles which contain longer alkyl chain substituents exhibit much better compatibility with polymer chains. That may be an explanation for high thermal stability of polyolefin/POSS nanocomposites containing POSS18 nanofiller and for the increase in the values of $T_{5}$ with the increasing mass $\%$ content of POSS18 as observed for those materials.

SEM images confirmed high compatibility between the POSS18 particles and polymeric matrices. The surface of PP/POSS18 nanocomposites (Fig. 8b) was more homogenous than the surface of PP/POSS8 nanocomposites (Fig. 8a), and no aggregates were visible.
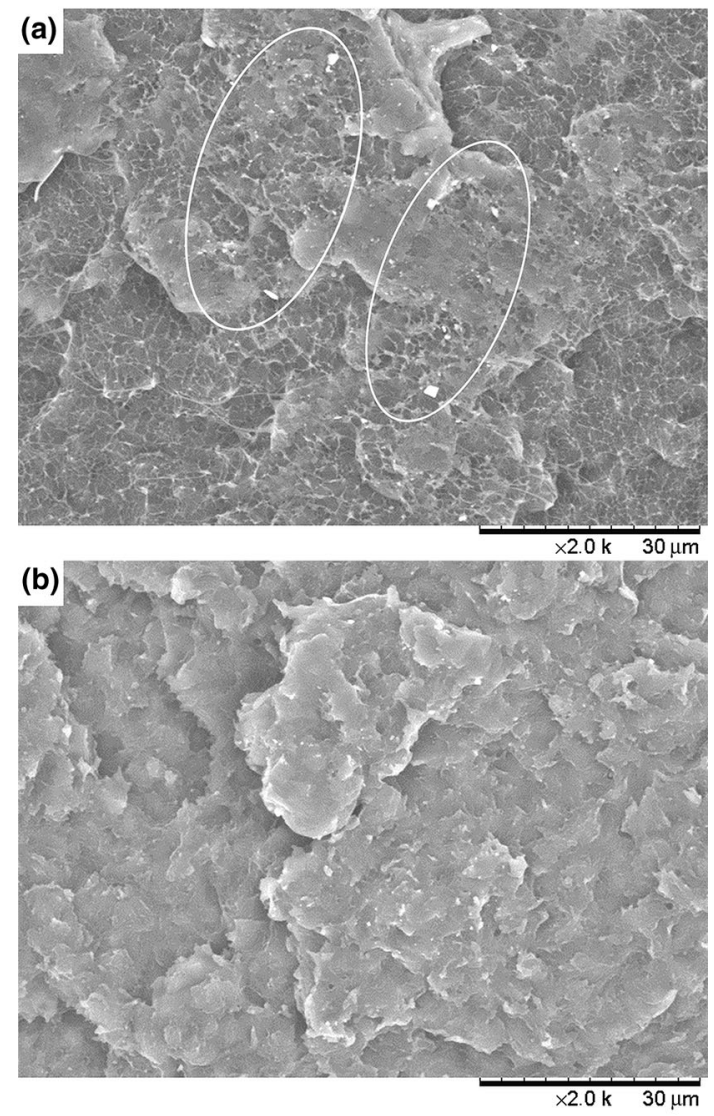

Fig. 8 SEM micrographs of a HDPE/5 \%POSS 8 and b HDPE/ $5 \%$ POSS18 nanocomposites
Incorporation of POSS with branched alkyl substituents on the silicon-oxygen core (POSS7b) into the HDPE matrix contributed to the increased thermal stability of nanocomposites which was improving with the increasing amount of the POSS7b nanofiller in the composite, probably because of high thermal stability of the neat POSS7b compound in air.

\section{Conclusions}

Thermal properties of POSS-containing polyolefin nanocomposites were investigated by differential scanning calorimetry (DSC) and thermogravimetric analysis (TG). The effects of the structure of alkyl substituents attached to the silicon-oxygen POSS core ( $n$-octyl, $n$-octadecyl and 4-methyl-hexyl) were studied. Also, the effects of the mass\% contents of the POSS nanofiller in the PP, LDPE and HDPE matrices on the crystallization behavior, melting behavior and thermal stability of obtained nanocomposites were determined.

The values of the peak and endset crystallization temperatures generally increased after incorporation of POSS nanofillers into a polyolefin matrix, irrespectively of the kind of POSS and the polymeric matrix. The changes in the values of onset crystallization temperatures were less systematic. In the case of PP/POSS and LDPE/POSS nanocomposites, the effect of POSS particles as effective nucleating agents which improved the crystallization process for polymeric materials was clearly demonstrated. Moreover, POSS with $n$-octyl substituents had the most significant impact on the crystallization process of polyolefin/POSS nanocomposites. The increasing mass $\%$ content of POSS nanofillers improved their effectiveness as nucleating agents. This effect was not observed for HDPE/ POSS nanocomposites, probably due to high crystallinity of HDPE and better spatial arrangement of its macrochains.

Incorporation of POSS molecules into polyolefin matrix resulted generally in the decreased melting temperature values for nanocomposite materials obtained. The impact of POSS particles, acting as nucleating agents, on melting behavior of polyolefin/POSS nanocomposites was described for the first time. A more significant influence of POSS nanofillers on the crystallization process of the obtained materials was clearly related to their decreased melting temperatures. Moreover, the crystallinity degree of polyolefin/POSS nanocomposites was increased with increasing mass\% content of POSS nanofillers in these materials.

The structures of alkyl substituents in POSS molecules affected their thermal stability. Taking into account the values of $T_{5}$ and $T_{\max }$, thermal stability of neat POSS compounds increased as follows: POSS7b $<$ POSS $8<$ POSS 18 under nitrogen and POSS $18<$ POSS7b $<$ POSS 8 in air. 
Thermal degradation of polyolefin nanocomposites-as assessed by TG under nitrogen-turned out different depending on the kind of the polyolefin matrix applied. In the case of PP and LDPE nanocomposites, the values of $T_{5}$ were higher in comparison with neat PP. The values of $T_{\max }$ for POSS-containing nanocomposites of PP and LDPE were consisted with those for neat polymers. In turn, addition of POSS particles into HDPE decreased the values of $T_{5}$ and $T_{\max }$. Irrespective of the kind of the polyolefin matrix, the nanocomposites with POSS18 were characterized by the highest thermal stability when tests were performed under nitrogen.

Thermal stability of POSS-containing polyolefin nanocomposites in air was improved significantly compared with neat polyolefins, especially at higher contents of POSS nanofiller. Nanocomposites with the POSS18 nanofiller were characterized by the highest thermal stability in comparison with nanocomposites containing POSS8 and POSS7b. This improvement was attributed to the improved compatibility and dispersion for POSS with long alkyl chain substituents in polyolefin matrices. A more uniform dispersion of POSS18 particles in polyolefin matrices in comparison with another POSS nanofillers applied was confirmed by the SEM analysis.

Acknowledgements Arkadiusz Niemczyk is recipient of the project "Ph.D. scholarships-investment in scientific staff of Opole voivodeship" co-funded by the European Union within the European Social Fund.

Open Access This article is distributed under the terms of the Creative Commons Attribution 4.0 International License (http://creative commons.org/licenses/by/4.0/), which permits unrestricted use, distribution, and reproduction in any medium, provided you give appropriate credit to the original author(s) and the source, provide a link to the Creative Commons license, and indicate if changes were made.

\section{References}

1. Kickelbick G. Hybrid materials. 1st ed. Wienheim: Wiley VCH; 2006.

2. Markovic E, Constantopolous K, Matisons JG. Polyhedral oligomeric silsesquioxanes: from early and strategic development through to materials application. In: Hartmann-Thompson C, editor. Applications of polyhedral oligomeric silsesquioxanes. In: Matisons J, series editor. Advances in Silicon Science 3. Springer Science \& Business Media BV; 2011. p. 1-46.

3. Njuguna S, Ansari F, Sachse S, Zhu H, Rodriguez VM. Nanomaterials, nanofillers, and nanocomposites: types and properties. In: Njuguna J, Pielichowski K, Zhu H, editors. Health and environmental safety of nanomaterials. Cambridge: Woodhead Publishing; 2014. p. 3-27.

4. Pielichowski K, Njuguna J, Janowski B, Pielichowski J. Polyhedral oligomeric silsesquioxanes (POSS)-containing nanohybrid polymers. Adv Polym Sci. 2006;201:225-96.

5. Wu J, Mather PT. POSS polymers: physical properties and biomaterials applications. J Macromol Sci Polym Rev. 2009;49: 25-63.
6. Li G, Wang L, Ni H, Pittman JCU. Polyhedral oligomeric silsesquioxane (POSS) polymers and copolymers: a review. J Inorg Organomet Polym. 2001;11:123-54.

7. Kuo SW, Chang FC. POSS related polymer nanocomposites. Prog Polym Sci. 2011;36:1649-96.

8. Baney RH, Itoh M, Sakakibara A, Suzuki T. Silsesquioxanes. Chem Rev. 1995;95:1409-30.

9. Cordes DB, Lickiss PD, Rataboul F. Recent developments in the chemistry of cubic polyhedral oligosilsesquioxanes. Chem Rev. 2010;110:2081-173.

10. Fina A, Tabuani D, Carniato F, Frache A, Boccaleri E, Camino G. Polyhedral oligomeric silsesquioxanes (POSS) thermal degradation. Thermochim Acta. 2006;440:36-42.

11. Williams KG, Gido SP, Coughlin EB. Polymers and copolymers containing covalently bonded polyhedral oligomeric silsesquioxanes moieties. In: Hartmann-Thompson C, editor. Applications of polyhedral oligomeric silsesquioxanes. In: Matisons J, series editor. Advances in Silicon Science 3. Springer Science \& Business Media BV; 2011. p. 167-207.

12. Pisuchpen T, Intasanta V, Hoven VP. Highly porous organicinorganic hybrid fiber from copolymers of styrene and polyhedral oligomeric silsesquioxane-derived methacrylate: syntheses, fiber formation and potential modification. Eur Polym J. 2014;60:38-48.

13. Hartmann-Thompson C. Polyhedral oligomeric silsesquioxanes in electronics and energy applications. In: Hartmann-Thompson $\mathrm{C}$, editor. Applications of polyhedral oligomeric silsesquioxanes. In: Matisons J, series editor. Advances in Silicon Science 3. Springer Science \& Business Media BV; 2011. p. 247-325.

14. Tanaka K, Chujo Y. Advanced functional materials based on polyhedral oligomeric silsesquioxane (POSS). J Mater Chem. 2012;22:1733-46.

15. McCusker C, Carroll JB, Rotello VM. Cationic polyhedral oligomeric silsesquioxane (POSS) units as carriers for drug delivery processes. Chem Commun. 2005;8:996-8.

16. Ayandele E, Sarkar B, Alexandridis P. Polyhedral oligomeric silsesquioxane (POSS)-containing polymer nanocomposites. Nanomater. 2012;2:445-75.

17. Blanco I, Abate L, Bottino FA. Variously substituted phenyl hepta cyclopentyl-polyhedral oligomeric silsesquioxane (ph, hcpPOSS)/polystyrene (PS) nanocomposites. J Therm Anal Calorim. 2013;112:421-8.

18. Marquis DM, Guillaume E, Chivas-Joly C. Properties of nanofillers in polymer. In: Cuppoletti J, editor. Nanocomposites and polymers with analytical methods. Rijeka: InTech; 2011. p. 261-84.

19. Krasnov AP, Aderikha VN, Afonicheva OV, Mit VA, Tikhonov NN, Vasil'kov AY, Said-Galiev EE, Naumkin AV, Nikolaev AY. Categorization system of nanofillers to polymer composites. J Frict Wear. 2010;31:68-80.

20. Fina A, Tabuani D, Frache A, Camino G. Polypropylene-polyhedral oligomeric silsesquioxanes (POSS) nanocomposites. Polymer. 2005;46:7855-66.

21. Pracella M, Chionna D, Fina A, Tabuani D, Frache A, Camino G. Polypropylene-POSS nanocomposites: morphology and crystallization behaviour. Macromol Symp. 2006;234:59-67.

22. Fu BX, Yang L, Somani RH, Zong SX, Hsiao BS, Phillips S, Blanski R, Ruth P. Crystallization studies of isotactic polypropylene containing nanostructured polyhedral oligomeric silsesquioxane molecules under quiescent and shear conditions. J Polym Sci Polym Phys. 2001;39:2727-39.

23. Fina A, Abbenhuis HCL, Tabuani D, Frache A, Camino G. Polypropylene metal functionalised POSS nanocomposites: a study by thermogravimetric analysis. Polym Degrad Stab. 2006;91:1064-70.

24. Carniato F, Boccaleri E, Marchese L, Fina A, Tabuani D, Camino G. Synthesis and characterisation of metal isobutylsilsesquioxanes and their role as inorganic-organic nanoadditives for enhancing polymer thermal stability. Eur J Inorg Chem. 2007;4:585-91. 
25. Chen JH, Chiou YD. Crystallization behavior and morphological development of isotactic polypropylene blended with nanostructured polyhedral oligomeric silsesquioxane molecules. J Polym Sci Polym Phys. 2006;44:2122-34.

26. Frone AN, Perrin FX, Radovici C, Panaitescu DM. Influence of branched or un-branched alkyl substitutes of POSS on morphology, thermal and mechanical properties of polyethylene. Compos Part B Eng. 2013;50:98-106.

27. Perrin FX, Panaitescu DM, Frone AN, Radovici C, Nicolae C. The influence of alkyl substituents of POSS in polyethylene nanocomposites. Polymer. 2013;54:2347-54.

28. Baldi F, Bignotti F, Fina A, Tabuani D, Riccò T. Mechanical characterization of polyhedral oligomeric silsesquioxane/ polypropylene blends. J Appl Polym Sci. 2007;105:935-43.

29. Chen JH, Yao BX, Su WB, Yang YB. Isothermal crystallization behavior of isotactic polypropylene blended with small loading of polyhedral oligomeric silsesquioxane. Polymer. 2007;48:1756-69.

30. Bouza R, Barral L, Diez FJ, Lopez J, Montero B, Rico M, Ramirez C. Study of thermal and morphological properties of hybrid system, iPP/POSS. Effect of flame retardance. Compos Part B Eng. 2014;58:566-72.

31. Heeley EL, Hughes DJ, Taylor PG, Bassindale AR. Crystallization and morphology development in polyethylene-octakis( $n$ octadecyldimethylsiloxy)-octasilsesquioxane nanocomposite blends. RSC Adv. 2015;5:34709-19.

32. Heeley EL, Hughes DJ, Aziz YE, Taylor PG, Bassindale AR. Morphology and crystallization kinetics of polyethylene/long alkyl-chain substituted polyhedral oligomeric silsesquioxanes (POSS) nanocomposite blends: a SAXS/WAXS study. Eur Polym J. 2014;51:45-56.

33. Joshi M, Butola BS, Simon G, Kukaleva N. Rheological and viscoelastic behavior of HDPE/Octamethyl-POSS Nanocomposites. Macromolecules. 2006;39:1839-49.

34. Filho NLD, Aquino HA, Pires G, Caetano L. Relationship between the dielectric and mechanical properties and the ratio of Epoxy resin to hardener of the hybrid thermosetting polymers. J Braz Chem Soc. 2006;17:533-41.

35. Wunderlich B, Czornyj G. A study of equilibrium melting of polyethylene. Macromolecules. 1977;10:906-13.

36. Butler MF, Donald AM, Bras W, Mant GR, Derbyshire GE, Ryan AJ. A real-time simultaneous small- and wide-angle X-ray scattering study of in-situ deformation of isotropic polyethylene. Macromolecules. 1995;28:6383-93.
37. Schawe JEK. The Gibbs free energy difference between a supercooled melt and the crystalline phase of polymers. J Therm Anal Calorim. 2015;120:1417-25.

38. Galeski A. Crystallization. In: Karger-Kocsis J, editor. Polypropylene: an A-Z reference. Dordrecht: Kluwer Publishers; 1999. p. 135-41.

39. Da Silva ALN, Tavares MIB, Politano DP, Coutinho FMB, Rocha MCG. Polymer blends based on polyolefin elastomer and polypropylene. J Appl Polym Sci. 1997;66:2005-14.

40. Genovese A, Shanks RA. Crystallization and melting of isotactic polypropylene in response to temperature modulation. J Therm Anal Calorim. 2004;75:233-48.

41. Shanks RA, Tiganis BE. Nucleating agents for thermoplastics. In: Pritchard G, editor. Plastics additives. London: Chapman \& Hall; 1998. p. 464-71.

42. Fina A, Tabuani D, Camino G. Polypropylene-polysilsesquioxane blends. Eur Polym J. 2010;46:14-23.

43. Fina A, Tabuani D, Peijs T, Camino G. POSS grafting on PPgMA by one-step reactive blending. Polymer. 2009;50:218-26.

44. Butola BS, Joshi M, Kumar S. Hybrid organic-inorganic POSS (Polyhedral oligomeric silsesquioxane)/Polypropylene nanocomposite filaments. Fibers Polym. 2010;11:1137-45.

45. Carniato F, Fina A, Tabuani D, Boccaleri E. Polypropylene containing Ti- and Al-polyhedral oligomeric silsesquioxanes: crystallization process and thermal properties. Nanotechnology. 2008; 19:475701.

46. Wang L, Wang YN, Huang ZG, Weng YX. Heat resistance, crystallization bevavior, and mechanical properties of polylactide/nucleating agent composites. Mater Des. 2015;66:7-15.

47. Huang X, Xie L, Jiang P, Wang G, Yin Y. Morphology studies and ac electrical property of low density polyethylene/octavinyl polyhedral oligomeric silsesquioxane composite dielectrics. Eur Polym J. 2009;45:2172-83.

48. Fina A, Abbenhuis HCL, Tabuani D, Camino G. Metal functionalized POSS as fire retardants in polypropylene. Polym Degrad Stab. 2006;91:2275-81.

49. Grassie N, Scott G. Polymer degradation and stabilization. Cambridge: Cambridge University Press; 1985.

50. Allen NS, Edge M. Fundamentals of polymer degradation and stabilization. London: Elsevier Applied Science; 1992. p. 1-21. 